\title{
Coexistent antiphospholipid syndrome and myeloproliferative neoplasm
}

\author{
Authors: \\ Dr. Zara Sayar ${ }^{1}$ MRCP FRCPath; Clinical Research Fellow \\ Dr. Susanna Nallamilli ${ }^{1,2}$ MBChB BSc; Clinical Research Fellow \\ Dr. Maria Efthymiou ${ }^{1,2}$ BSc MSc PhD; Senior Research Associate \\ Dr. Jonathan Lambert ${ }^{2}$ PhD FRCP FRCPath; Consultant Haematologist \\ Prof. Hannah Cohen ${ }^{1,2}$ MD FRCP FRCPath; Consultant Haematologist and Professor of \\ Haematology
}

\section{Affiliations:}

${ }^{1}$ Haemostasis Research Unit, Department of Haematology, University College London, London, UK

${ }^{2}$ Department of Haematology, University College London Hospitals NHS Foundation Trust, London, UK

\section{Corresponding author:}

Dr Zara Sayar, Department of Haematology, University College London, 1st Floor, 51 Chenies Mews, London WC1E 6HX.

Tel: $+44(0) 203$ 447-9456

e-mail: zara.sayar@nhs.net

Abstract word count:193/200 
Manuscript word count: 2560/3000

Number of tables: 1

Number of figures: 1

Number of references: $43 / 60$ 


\section{Abstract}

Antiphospholipid syndrome (APS) and myeloproliferative neoplasms (MPN) are associated with an increased risk of thrombosis. The optimal management of patients with coexistent APS and MPN has not been defined. A single centre and systematic literature review of patients with coexistent APS and MPN was performed. Cases were divided into two groups based on whether they met international consensus criteria for APS. Of the 12 studies identified, eight were excluded (leaving five of a total 54 patients), as although antiphospholipid antibodies (aPL) were documented, the diagnosis of APS was not conclusively demonstrated. Another ten patients with definite APS were identified at our centre. Fifteen patients (ten females, five males) were therefore included in this analysis (eleven definite APS and four likely), median age 44 (range: 13-71) years. Nine had polycythaemia vera and six, essential thrombocythaemia. Amongst the 15 patients there were six venous, six arterial, two microvascular events, and two cases of obstetric morbidity. Nine patients were single-positive, and six double-positive for aPL. None were triple aPLpositive. Four thrombotic patients at our centre had recurrent thrombotic/obstetric events, including while on anticoagulation/antiplatelet treatment. Identification of MPN in APS patients can inform thrombotic risk assessment.

Keywords: Myeloproliferative neoplasm, antiphospholipid syndrome, antiphospholipid antibodies, venous thromboembolism, arterial thrombosis, microvascular thrombosis 


\section{Introduction}

Antiphospholipid syndrome (APS) is an acquired autoimmune thrombophilia defined by thrombosis (venous, arterial or microvascular) and/or obstetric complications in the context of persistent antiphospholipid (aPL) antibodies: lupus anticoagulant (LA), IgG and/or IgM anti-beta-2 glycoprotein-1 (aß2GP1) and/or anticardiolipin antibodies (aCL) (1). The standard treatment of arterial and venous thrombosis in APS is anticoagulation with warfarin or an alternative vitamin $\mathrm{K}$ antagonist (VKA). For venous thromboembolism (VTE), standard intensity warfarin (target 2.5 [range 2.0-3.0]) is the preferred treatment option. The European Medicines Agency (EMA) states that direct oral anticoagulants (DOACs) are not recommended for APS patients, especially those who are triple aPL-positive, i.e. have LA, $\lg$ and/or IgM aß2GP1 and aCL (2). British Society for Haematology and International Society on Thrombosis and Haemostasis guidance advise that DOACs may be considered following a first VTE in single- and double aPL-positive APS patients, and should be avoided in those who are triple-positive $(3,4)$. There is a lack of substantive data on the management of APS and arterial thrombosis, however standard intensity VKA, with or without an antiplatelet agent, or high-intensity VKA (target 3.5 [range 3.0-4.0]) is advocated (5-7). The annual risk of recurrent thrombosis in APS while taking a VKA was up to $4.0 \%$ and $3.1 \%$ in two randomised controlled trials (RCTs); $(8,9) 4.3 \%$ in a prospective observational cohort study of 1,000 APS patients;(10) and $4.8 \%$ in a retrospective cohort study of triple aPLpositive APS patients (11).

The commonest $B C R-A B L$ negative myeloproliferative neoplasms (MPN) are polycythaemia vera (PV), essential thrombocythaemia (ET) and primary myelofibrosis (PMF). Patients with MPN are at increased risk of venous and arterial thrombosis, sometimes combined with a significant bleeding risk (12). Thrombotic events are more frequent in PV than in ET and MF, and venous thrombosis can occur in unusual sites such as splanchnic vein thrombosis, even 
in those with a normal full blood count (13). These events significantly contribute to morbidity and mortality (14). Adverse pregnancy outcomes are more common in patients with MPN: in a study of 151 women with ET and no previous history of thrombosis, $26.5 \%$ ( $n=40 / 151)$ had a miscarriage (15). This is compared with a reported risk of miscarriage in the general population of between $11-22 \%$ (16).

The risk of thrombotic events for patients with MPN can be stratified into low-, intermediateand high-risk categories, primarily based on the patient's age and history of previous thrombosis (17). For those in the high-risk group, there is clear evidence that cytoreduction reduces the rate of thrombotic complications (18). In a randomised study of 114 high-risk ET patients, hydroxycarbamide plus aspirin significantly lowered the incidence of thrombotic events compared to aspirin alone ( $n=2 / 56,3.6 \%$, vs. $n=14 / 58$ patients, $24 \%, p=0.003)(19)$. In the PT-1 trial, 809 patients with high-risk ET were randomised to receive either anagrelide or hydroxycarbamide (in addition to aspirin) (20). After a median follow-up of 39 months, the rates of arterial thrombosis and serious haemorrhage were significantly higher, and the rate of VTE significantly lower, in the anagrelide arm compared to the hydroxycarbamide arm, despite equivalent long-term control of platelet counts (20).

For MPN patients who develop VTE, the use of antithrombotic treatment should be coupled with special care to manage bleeding risk factors, particularly considering that thrombocytosis is associated with platelet function defects (21). The risk of recurrent VTE in MPN was reported as $6 \%$ per patient/year in a single-centre, retrospective study including 526 patients. In those with recurrent events, only three of 35 (9\%) occurred on anticoagulation, suggesting a prolonged period of anticoagulation may be beneficial in this cohort (22). In a single retrospective study, recurrence after TIA/stroke in patients with MPN was estimated at 1.18 per 100 patient-years (23). 
A small number of studies have reported $\mathrm{APL}$ as a potential biomarker to assess thrombotic risk in MPN patients. In these studies a diagnosis of APS is not confirmed. In a study of 160 patients with primary Budd Chiari Syndrome were assessed for an underlying thrombotic disorder. 50/103 (49\%) had MPN (PV $n=27$, ET $n=9$, idiopathic myelofibrosis $n=2$, unclassified $n=11$ ) and $37 / 150(25 \%)$ had aPL (24). One cohort study of 68 patients with ET identified a higher prevalence of aPL (IgM aCL and aß2GP1, titres unreported) compared with healthy controls, suggesting that aPL levels may aid in identifying MPN patients at highest risk of thrombosis, particularly IgM aß2GP1 (25). Assessment of aPL in 50 patients with MPN compared with 30 controls demonstrated that $\operatorname{lgM}$ aCL were present in $11 / 50$ $(22 \%)$ compared with $1 / 30(3 \%)$ in the control arm $(p<0.021)(26)$.

In summary, both APS and MPN are associated with an increased risk of thromboembolism, venous, arterial and microvascular. However, coexistence of both disorders would expect to confer a higher risk of thrombosis or recurrence. We report herein a single centre and literature review of patients with coexistent APS and MPN.

\section{Methods}

\section{Systematic review}

A literature search was conducted in line with the PRISMA guidelines to search for all published articles up till and including January 2019. Three independent researchers (SN, ZS, ME) performed searches of the world literature using the databases PubMed, Cochrane Library, and Web of Knowledge. The PubMed MeSH terms were: 'antiphospholipid syndrome', ‘anti-phospholipid syndrome', 'lupus anticoagulant', 'anticardiolipin', 'myeloproliferative disease', 'myeloproliferative neoplasm', 'MPN', 'polycythaemia rubra 
vera', 'polycythaemia', 'PCV', 'essential thrombocytosis', 'essential thrombocythaemia', 'ET', 'myelofibrosis'. We applied the following filters: English language, abstract available. References from original articles were also examined; no further relevant publications were identified, thus ensuring quality of the initial search. Patients were included if they met the criteria for APS i.e persistent positivity (>12 weeks apart) for medium positive IgG and/lgM aCL and/or aß2GP1 and/or LA (1). Patients were considered to have 'highly likely' APS if: i) positive aPL but persistence of aPL (>12 weeks apart) and/or titre or isotype of antibody was not documented; ii) or if it was likely that the international consensus criteria were met for vascular thrombosis, but not confirmed. Electronic clinic records were searched using the terms 'APS', 'MPN', 'PV' and 'ET' at University College Hospital (UCLH), London. Data was extracted and reviewed.

\section{Results}

Our systematic review identified 12 abstracts that reported cases with concurrent MPN and aPL. The full texts of these articles were analysed carefully by two researchers (ZS \& SN). Eight studies (49 patients) were excluded due to incomplete APS diagnosis. Although these articles mentioned the presence of $\mathrm{aPL}$, it was not clear whether the criteria to fulfil APS diagnosis were fulfilled e.g. persistent aPL 12 weeks apart (1) (Figure 1). Five cases from four publications were assessed to have either fulfilled or were highly likely to have a diagnosis of APS. Ten further cases were identified in our own cohort of patients based at UCLH.

Patient demographics, aPL status and clinical histories are summarised in table 1. Ten of the 15 patients were female, with a median age of 44 (range 13 - 71) years. Nine had a diagnosis of PV and 6 ET. None had PMF. Thirteen of the 15 patients (86.7\%) had 
thrombotic APS (seven with initial venous events and six arterial) and two (13.3\%) had obstetric APS.

Nine patients were single aPL-positive, and six double aPL-positive. None were triplepositive. Eight of the 15 patients had aLA, with IgG and IgM aß2GP1 in 2/15 and 4/15, respectively, and $\lg G$ and $\operatorname{lgM}$ aCL antibodies in $4 / 15$ and $3 / 15$, respectively (the isotype of one aCL was not stated). Two patients at our institution fulfilled the criteria for obstetric APS, both single-positive for LA.

\section{Venous thromboembolic events}

Five patients experienced only venous events, with one in combination with obstetric morbidity and another with arterial thrombosis. The seven venous thromboses included; cerebral thrombosis $(n=2)$, deep vein thrombosis (DVT) $(n=3)$, Budd Chiari syndrome $(n=1)$ and portal vein thrombosis $(n=1)$. Four were LA positive, one had moderate/high titre $\lg M$ aß2GP1 antibodies and three IgG aCL antibodies. Three patients had ET and four PV. Treatment included: five patients with standard intensity warfarin target INR 2.5 (range 2.03.0) without antiplatelet therapy, one with apixaban $5 \mathrm{mg}$ twice daily and one with warfarin target 3.0 (range 2.5-3.5) and low dose aspirin (LDA) 75mg once daily.

\section{Arterial and microvascular events}

Six patients had seven arterial events (one in combination with a venous event). These comprised cerebral infarct $(n=3)$, splenic artery occlusion $(n=1)$, transient ischaemic attack $(n=1)$, aortic valve thrombus $(n=1)$ and brachial artery thrombosis $(n=1)$. Five had a diagnosis of PV and one ET. Three patients had moderate/high titre aß2GP1 (two with IgM and one with IgG). Moderate/high titre aCL were present in five patients (two with $\lg \mathrm{M}$, one 
with IgG and one unknown isotype). Three were LA positive. Two patients were treated with standard-intensity warfarin and LDA, one with intermediate-intensity warfarin, target INR 3.0 (range 2.5-3.5) plus LDA and one with high-intensity warfarin target INR 3.5 (range 3.0-4.0) without the use of aspirin. Two patients received VKA (without LDA) with no information on target INR range provided as not treated at UCLH.

Two patients had microvascular events including erythromelalgia and necrotic toe. One had a diagnosis of $\mathrm{PV}$ and the other ET. Both patients had moderate/high titre aCL (one with IgG and the other with $\lg M$ ) and one patient also had $\lg G$ aß2GP1. Erythromelalgia was treated with $100 \mathrm{mg}$ aspirin alone and the necrotic toe was treated with warfarin (target INR not documented) and an antiplatelet agent.

\section{APS-related obstetric morbidity}

Two patients had obstetric APS manifested by second trimester miscarriages. Patient five (table 1) presented with a miscarriage at 19 weeks gestation and patient 12 (table 1) is reported to have previously had 20 miscarriages between 12 and 16 gestation weeks. Both patients had ET with LA positivity. They were both carriers of the JAK2 V617F mutation.

\section{Recurrent events}

Four patients (table 1) at our centre had recurrent events, including while on anticoagulation (together with LDA in a patient with obstetric morbidity). Patient 3 presented with an extensive cerebral venous sinus thrombosis (CVST) initially, and had a recurrent CVST two years after her initial presentation, associated with a subtherapeutic INR on warfarin at 1.1 (target range 2.0-3.0). After a period on $\mathrm{LMWH}$, the target INR range was increased to 2.53.5 but due to erratic INRs, she was subsequently switched to rivaroxaban $20 \mathrm{mg}$ od (weight 
$62.5 \mathrm{~kg}$ ), following which, she developed splenic vein thrombosis. Again, a period of LMWH was followed by reinitiating warfarin at high intensity.

Patient 6 presented with an arterial event (ischaemic stroke), and subsequently had a further ischaemic stroke ten years later while on warfarin and LDA. The INR was subtherapeutic at 1.4 , target range $3.0-4.0,3.0-3.5$ ideal) on the day of this event during bridging prior to a colonoscopy. The target INR range was subsequently modified to 3.5-4.0 ideal following this second event, at which point the LDA was discontinued.

Patient 12 developed TIAs while on warfarin target INR range 2.0-3.0 for previous VTE (prior to diagnosis of APS), but on admission with her first TIA, the INR was subtherapeutic at 1.4. She was discharged on bridging LMWH but represented seven days later with recurrent TIA (INR 2.5). Her INR range was subsequently increased to INR range 3.0-4.0, 3.0-3.5 ideal.

Patient 5 with obstetric APS initially presented with a miscarriage at 19 weeks gestation. An ultrasound scan demonstrated fetal growth restriction. At autopsy, a placental biopsy showed infarction. During a subsequent pregnancy she was treated with LDA and prophylactic dose $\mathrm{LMWH}$, initiated at four weeks gestation. Despite this, she experienced a first trimester miscarriage at nine weeks gestation. Her third pregnancy was treated with aspirin $150 \mathrm{mg}$ once daily and intermediate dose LMWH started at four weeks gestation, despite which she had a further miscarriage at eight weeks. There was no chromosomal analysis of the fetus.

\section{Bleeding events}

Three patients experienced bleeding complications (table 1). Patient 3 was re-warfarinsed, aiming for a high intensity INR. A week after starting warfarin, while also on once daily 
standard therapeutic dose bridging $\mathrm{LMWH}$, presented at the hospital with back pain and was found to have bilateral adrenal haemorrhages. The INR at the time was 2.7. The antiplatelet agent had been discontinued when warfarin was initiated.

Patient 4 experienced recurrent episodes of mild macroscopic haematuria with her urine described as being pink for two months while on standard-intensity warfarin, with no identifiable cause on CT scan. This resolved spontaneously.

Patient 12 experienced minor intermittent epistaxis while on standard-intensity warfarin. She had two to three episodes in one year so was referred for an ear, nose and throat specialist opinion.

\section{Discussion}

This systematic review and service evaluation in a single institution has identified 15 patients with coexistent APS (10 confirmed, 5 highly likely) and MPN, nine with PV and six with ET. The majority $(13 / 15,86.7 \%)$ had thrombotic APS, seven with initial venous events and six arterial; and two (13.3\%) had obstetric APS. The aPL phenotype was single aPL-positive in nine patients and double aPL-positive in six. Identification of coexistent APS and MPN may influence patient management such as in the case of arterial events where antiplatelet agents, rather than anticoagulation is standard treatment $(5-7,27)$.

The pathophysiological basis for an association between aPL and MPN is undefined. MPN is reported to be significantly associated with prior autoimmune disease such as polymyalgia rheumatica and Crohn's disease $(28,29)$. It has been suggested that patients with ET may be more likely to form aPL due to increased negative charge on platelet phospholipid 
membranes (30). $\beta 2 \mathrm{GP} 1$ binds to membrane phospholipids, which subsequently undergo a conformational change, exposing epitopes for certain aPL subtypes (31). Exposure of phospholipid binding proteins such as $\beta 2 \mathrm{GP1}$ and endothelial damage may trigger aPL formation (32). The aPL- $\beta 2$ GP1 complex can bind to and activate endothelial cells, platelets and monocytes and aPL binding to these cells can upregulate monocyte expression of tissue factor, a potent initiator of coagulation $(30,32,33)$. Neutrophil extracellular traps (NETs) play a key role in the development of both arterial and venous thrombosis (34). Anti-NET antibodies in patients with primary APS are elevated and they may impair NET clearance as well as activating the complement cascade (35). JAK2 V617F expression has been linked to the formation of NETs and thrombosis and it has been suggested that inhibiting JAK2 V617F may reduce thrombosis in MPN (36).

The potential clinical consequences of coexistent APS and MPN merits consideration. No patients were found to be triple aPL-positive, the aPL phenotype considered to be associated with the highest thrombotic risk $(37,38)$. Four patients had recurrent events, including while on anticoagulation (together with LDA in a patient with obstetric morbidity). Recurrent events were predominantly in the same arterial or venous system as the initial event, which has been demonstrated in APS and MPN patients (39-41). One patient had a recurrent event while on a $\operatorname{DOAC}(3,42,43)$. The nature of the association between APS and MPN, as well as potential clinical consequences requires definition. This is clinically relevant to guide optimal management of antithrombotic strategies. Identification of underlying pathophysiological mechanisms could inform management approaches.

A key strength of this work is its novelty. It provides direction for studies to elucidate the relationship between APS and MPN and define the impact on clinical practice. Limitations are the retrospective nature of data collection and the small number of patients. 
In conclusion, patients with a new thrombosis, particularly arterial, and MPN should be considered for APS assessment as this could lead to a change in management, namely with the use of a VKA rather than antiplatelet agents alone.

\section{Acknowledgments}

ZS, SN and ME performed the literature review, collected and analysed the data. All authors contributed to writing the paper 
MEDLINE ( $n=267)$, EMBASE

( $n=62$ ) and the Cochrane

database $(n=13)$

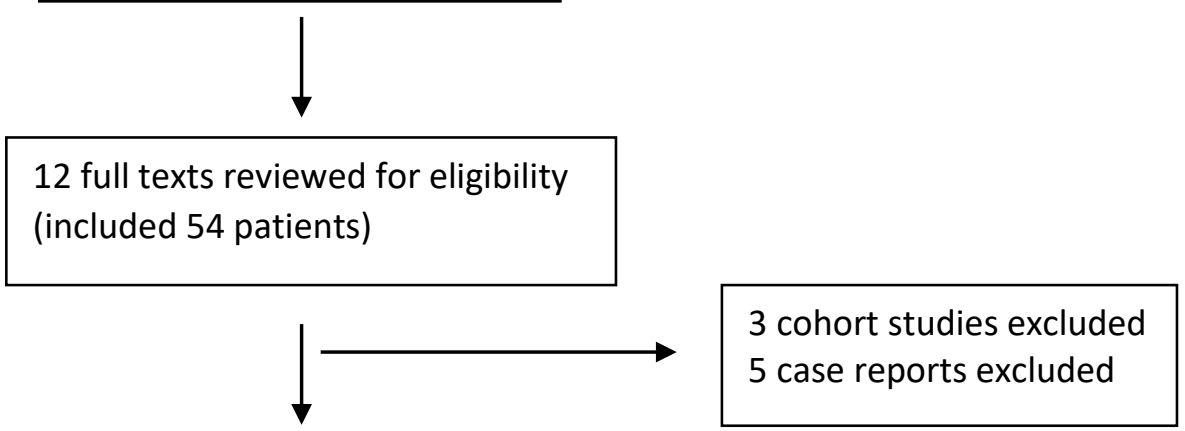

Total:

4 studies included (5 patients)

10 cases at $\mathrm{UCLH}$

Figure 1: Study flow diagram 


\begin{tabular}{|c|c|c|c|c|c|c|c|c|c|c|c|}
\hline No & Sex & Age & $\begin{array}{l}\text { MPN } \\
\text { type }\end{array}$ & Mutation & MPN Treatment & LA & $\mathrm{aCL}$ & aß2GP1 & $\begin{array}{l}\text { Presenting } \\
\text { arterial/venous event or } \\
\text { obstetric morbidity }\end{array}$ & $\begin{array}{l}\text { Blood results at } \\
\text { time of } \\
\text { thrombotic event }\end{array}$ & $\begin{array}{l}\text { Initial treatment for } \\
\text { thrombosis/obstetric } \\
\text { morbidity }\end{array}$ \\
\hline $1 .{ }^{n}$ & $M$ & 71 & PV & JAK2 V617F & $\mathrm{HU}$ & - & - & $\lg G$ & $\begin{array}{l}\text { Arterial: Splenic artery } \\
\text { occlusion }\end{array}$ & $\begin{array}{l}\text { Het } 0.44 \\
\text { Plt } 440 \times 10^{9} / \mathrm{L}\end{array}$ & Warfarin (target INR 3.5) \\
\hline $2 . \wedge$ & $M$ & 21 & ET & $\begin{array}{l}\text { MPL Exon } 10 \\
\text { MPL W515K }\end{array}$ & $\mathrm{HU}$ & + & - & - & $\begin{array}{l}\text { Venous: } \\
\text { Transverse/sigmoid sinus } \\
\text { thrombosis }\end{array}$ & Plt $689 \times 10^{9} / \mathrm{L}$ & Warfarin (target INR 2.5) \\
\hline $3 . .^{n}$ & $\mathrm{~F}$ & 46 & PV & JAK2 V617F & Venesection HU & + & - & $\lg M$ & $\begin{array}{l}\text { Venous: Sagittal sinus } \\
\text { thrombosis }\end{array}$ & ND & Warfarin (target INR 2.5) \\
\hline $4 . .^{n}$ & $\mathrm{~F}$ & 36 & PV & JAK2 V617F & $\mathrm{HU}$, aspirin & - & $\lg M$ & $\lg M$ & Arterial: TIA & ND & Warfarin (target INR 2.5) \\
\hline $5 . \wedge$ & $\mathrm{F}$ & 33 & ET & JAK2 V617F & $\begin{array}{l}\text { PEG-IFN } \\
\text { aspirin }\end{array}$ & + & - & - & Obstetric morbidity & Plt $900 \times 10^{9} / \mathrm{L}$ & Aspirin $75 \mathrm{mg}$ OD \\
\hline $6 . \wedge$ & $\mathrm{F}$ & 28 & PV & JAK2 V617F & $\begin{array}{l}\text { HU, anagrelide } \\
\text { PEG-IFN } \\
\text { aspirin }\end{array}$ & + & - & $\lg M$ & Arterial: Cerebral infarct & ND & Warfarin (target INR 2.5) \\
\hline $7 .^{1}$ & $\mathrm{~F}$ & 44 & ET & NA & $\mathrm{HU}$ & + & IgM & - & Arterial: Cerebral infarct & ND & Warfarin (target INR ND) \\
\hline $8 .^{* 1}$ & $\mathrm{~F}$ & 62 & ET & NA & $\mathrm{HU}$, aspirin & - & $\operatorname{IgM}$ & - & $\begin{array}{l}\text { Microvascular: } \\
\text { Erythromelalgia }^{+}\end{array}$ & $\begin{array}{l}\text { Platelets 1000- } \\
1200 \times 10^{9} / \mathrm{L}\end{array}$ & NA \\
\hline 9. $* 2$ & $\mathrm{~F}$ & 47 & PV & NA & Anagrelide & + & $t^{*}$ & - & $\begin{array}{l}\text { Arterial: Aortic valve } \\
\text { thrombus }\end{array}$ & $\begin{array}{l}\mathrm{Hb} 119 \mathrm{~g} / \mathrm{L} \\
\text { Plt } 384 \times 10^{9} / \mathrm{L}\end{array}$ & Warfarin (target INR ND) \\
\hline $10 .^{* 3}$ & $\mathrm{~F}$ & 31 & PV & JAK2 V617F & $\begin{array}{l}\text { HU, antiplatelet } \\
\text { (ND) }\end{array}$ & - & $\lg G$ & IgG & $\begin{array}{l}\text { Microvascular: Necrotic } \\
\text { toe }\end{array}$ & $\begin{array}{l}\mathrm{Hb} 182 \mathrm{~g} / \mathrm{L} \\
\text { Hct } 0.538 \\
\text { Plt } 552 \times 10^{9} / \mathrm{L}\end{array}$ & VKA (target INR ND) \\
\hline $11 .^{* 4}$ & M & 13 & ET & NA & NA & + & - & - & $\begin{array}{l}\text { Venous: Budd Chiari } \\
\text { syndrome }\end{array}$ & $\begin{array}{l}\mathrm{Hb} 59 \mathrm{~g} / \mathrm{L} \\
\text { (microcytic, } \\
\text { hypochromic) } \\
\text { Plt } 689 \times 10^{9} / \mathrm{L}\end{array}$ & Warfarin (target INR 2.5) \\
\hline $12^{\wedge}$ & $\mathrm{F}$ & 70 & ET & JAK2 V617F & $\mathrm{HU}$ & + & - & - & $\begin{array}{l}\text { Venous: Portal vein } \\
\text { thrombosis } \\
\text { Obstetric morbidity }\end{array}$ & ND & Warfarin (target INR 2.5) \\
\hline $13^{n}$ & M & 71 & PV & JAKV617F & PEG-IFN, aspirin & - & $\lg G$ & - & $\begin{array}{l}\text { Arterial: Cerebral infarct, } \\
\text { Brachial artery thrombosis } \\
\text { Venous: DVT }\end{array}$ & ND & Warfarin (target INR 3.0) \\
\hline $14^{\wedge}$ & $M$ & 46 & PV & JAKV617F & NA & - & $\lg G$ & - & Venous: DVT & $\begin{array}{l}\mathrm{Hb} 133 \mathrm{~g} / \mathrm{L} \\
\text { Hct } 0.385 \\
\text { Plt } 281 \times 10^{9} / \mathrm{L}\end{array}$ & Apixaban $5 \mathrm{mg}$ twice daily \\
\hline
\end{tabular}


aß2GP1: anti-beta 2 glycoprotein 1 antibodies; aCL: anticardiolipin antibodies; ET: Essential thrombocythaemia; F: Female; HU: Hydroxycarbamide; LA: lupus anticoagulant; M: Male; MPN: Myeloproliferative neoplasm; NA: not applicable; ND: not documented; OD: once daily; PEG-IFN: pegylated interferon alpha; PV: Polycythaemia vera; TIA: Transient ischaemic attack; VKA: vitamin K antagonist; ^ University College London Hospital patient; * Likely APS, but unable to confirm if aPL testing to confirm persistence was $>12$ weeks apart and/or titre of antibodies; ${ }^{+}$Likely International consensus criteria met for vascular thrombosis, but unable to confirm; ${ }^{*}$ Isotype not documented 


\section{References}

1. Miyakis S, Lockshin MD, Atsumi T, Branch DW, Brey RL, Cervera R, et al. International consensus statement on an update of the classification criteria for definite antiphospholipid syndrome (APS). Journal of Thrombosis and Haemostasis. 2006;4:295-306.

2. European Medicines Agency. EMA/PRAC/219985/2019. Pharmacovigilance Risk Assessment Committee (PRAC). https://www.ema.europa.eu/en/documents/pracrecommendation/prac-recommendations-signals-adopted-8-11-april-2019-prac meeting_en.pdf. Updated 2019.

3. Zuily S, Cohen $\mathrm{H}$, Isenberg $\mathrm{D}$, et al., Use of direct oral anticoagulants in patients with thrombotic antiphospholipid syndrome: guidance from the scientific and standardization committee of the international society on thrombosis and haemostasis, J. Thromb. Haemost. 2020;18:2126-2137.

4. Arachchillage DR, Gomez K, Alikhan R, Anderson JA, Lester W, Laffan M, et al. Addendum to British Society for Haematology Guidelines on Investigation and Management of Antiphospholipid syndrome, 2012 (Br. J. Haematol. 2012; 157: 47-58): use of direct acting oral anticoagulants. Br J Haematol. 2020;189:212-5.

5. Holbrook A, Schulman S, Witt DM, Vandvik PO, Fish J, Kovacs MJ, et al. Evidence-based management of anticoagulant therapy: antithrombotic therapy and prevention of thrombosis: American College of Chest Physicians evidence-based clinical practice guidelines. Chest. 2012;141:e152S-84S.

6. Keeling D, Mackie I, Moore GW, Greer IA, Greaves M, British Committee for Standards in Haematology. Guidelines on the investigation and management of antiphospholipid syndrome. Br J Haematol. 2012;157:47-58. 
7. Tektonidou MG, Andreoli L, Limper M, Amoura Z, Cervera R, Costedoat-Chalumeau N, et al. EULAR recommendations for the management of antiphospholipid syndrome in adults. Ann Rheum Dis. 2019;78:1296-1304.

8. Crowther MA, Ginsberg JS, Julian J, Denburg J, Hirsh J, Douketis J, et al. A comparison of two intensities of warfarin for the prevention of recurrent thrombosis in patients with the antiphospholipid antibody syndrome. N Engl J Med. 2003;349:1133-8.

9. Finazzi G, Marchioli R, Brancaccio V, Schinco P, Wisloff F, Musial J, et al. A randomized clinical trial of high-intensity warfarin vs. conventional antithrombotic therapy for the prevention of recurrent thrombosis in patients with the antiphospholipid syndrome. Journal of Thrombosis and Haemostasis. 2005;3:848-53.

10. Cervera R, Khamashta MA, Shoenfeld Y, Camps MT, Jacobsen S, Kiss E, et al. Morbidity and mortality in the antiphospholipid syndrome during a 5-year period: a multicentre prospective study of 1000 patients. Ann Rheum Dis. 2009;68:1428-32.

11. Pengo V, Ruffatti A, Legnani C, Gresele P, Barcellona D, Erba N, et al. Clinical course of high-risk patients diagnosed with antiphospholipid syndrome. Journal of Thrombosis and Haemostasis. 2010;8:237-42.

12. Vannucchi AM, Harrison CN. Emerging treatments for classical myeloproliferative neoplasms. Blood. 2017;129:693-703.

13. Casini A, Fontana P, Lecompte TP. Thrombotic complications of myeloproliferative neoplasms: risk assessment and risk-guided management. Journal of Thrombosis and Haemostasis. 2013;11:1215-27.

14. Cervantes F, Passamonti F, Barosi G. Life expectancy and prognostic factors in the classic BCR/ABL-negative myeloproliferative disorders. Leukemia. 2008;22:905. 
15. Randi ML, Bertozzi I, Rumi E, Elena C, Finazzi G, Vianelli N, et al. Pregnancy complications predict thrombotic events in young women with essential thrombocythemia. Am J Hematol. 2014;89:306-9.

16. Ammon Avalos L, Galindo C, Li D. A systematic review to calculate background miscarriage rates using life table analysis. Birth Defects Research Part A: Clinical and Molecular Teratology. 2012;94:417-23.

17. Barbui T, Finazzi G, Falanga A. Myeloproliferative neoplasms and thrombosis. Blood, The Journal of the American Society of Hematology. 2013;122:2176-84.

18. Barbui T, Barosi G, Birgegard G, Cervantes F, Finazzi G, Griesshammer M, et al. Philadelphia-negative classical myeloproliferative neoplasms: critical concepts and management recommendations from European LeukemiaNet. J Clin Oncol. 2011;29:761-70.

19. Cortelazzo S, Finazzi G, Ruggeri M, Vestri O, Galli M, Rodeghiero F, et al. Hydroxyurea for patients with essential thrombocythemia and a high risk of thrombosis. $\mathrm{N}$ Engl $\mathrm{J}$ Med. 1995;332:1132-7.

20. Harrison CN, Campbell PJ, Buck G, Wheatley K, East CL, Bareford D, et al. Hydroxyurea compared with anagrelide in high-risk essential thrombocythemia. $\mathrm{N}$ Engl $\mathrm{J}$ Med. 2005;353:33-45.

21. Elliott MA, Tefferi A. Thrombosis and haemorrhage in polycythaemia vera and essential thrombocythaemia. Br J Haematol. 2005;128:275-90.

22. Wille K, Sadjadian P, Becker T, Kolatzki V, Horstmann A, Fuchs C, et al. High risk of recurrent venous thromboembolism in BCR-ABL-negative myeloproliferative neoplasms after termination of anticoagulation. Ann Hematol. 2019;98:93-100. 
23. De Stefano V, Za T, Rossi E, Vannucchi AM, Ruggeri M, Elli E, et al. Recurrent thrombosis in patients with polycythemia vera and essential thrombocythemia: incidence, risk factors, and effect of treatments. Haematologica. 2008;93:372-80.

24. Murad SD, Plessier A, Hernandez-Guerra M, Fabris F, Eapen CE, Bahr MJ, Trebicka J, Morard I, Lasser L, Heller J, Hadengue A. Etiology, management, and outcome of the BuddChiari syndrome. Annals of internal medicine. 2009;4;151:167-75.

25. Harrison C, Donohoe S, Carr P, Dave M, Mackie I, Machin S. Patients with essential thrombocythaemia have an increased prevalence of antiphospholipid antibodies which may be associated with thrombosis. Thromb Haemost. 2002;87:802-7.

26. Jensen MK, de Nully Brown P, Thorsen S, Hasselbalch HC. Frequent occurrence of anticardiolipin antibodies, Factor V Leiden mutation, and perturbed endothelial function in chronic myeloproliferative disorders. Am J Hematol. 2002;69:185-91.

27. Cohen H, Cuadrado MJ, Erkan D, Duarte Garcia A, Isenberg D, Knight J, et al. 16th International Congress on Antiphospholipid Antibodies Task Force Report on Antiphospholipid Syndrome Treatment Trends. Lupus 2020;29:1571-1593.

28. Janjetovic S, Beckmann L, Holstein K, Rolling C, Thiele B, Schafhausen P, et al. Prevalence of definite antiphospholipid syndrome in carriers of the JAK2V617F mutation. Thromb Res. 2020;198:55-61.

29. Kristinsson SY, Landgren O, Samuelsson J, Bjorkholm M, Goldin LR. Autoimmunity and the risk of myeloproliferative neoplasms. Haematologica. 2010;95:1216-20.

30. Harrison CN, Machin SJ. Antiphospholipid antibodies and essential thrombocythemia. Am J Med. 1997;102:317-8. 
31. Schreiber K, Sciascia S, De Groot PG, Devreese K, Jacobsen S, Ruiz-Irastorza G, et al. Antiphospholipid syndrome. Nature reviews Disease primers. 2018;4:1-20.

32. De Groot P, Urbanus R, Derksen R. Pathophysiology of thrombotic APS: where do we stand? Lupus. 2012;21:704-7.

33. Garcia D, Erkan D. Diagnosis and management of the antiphospholipid syndrome. N Engl J Med. 2018;378:2010-21.

34. Yalavarthi S, Gould TJ, Rao AN, Mazza LF, Morris AE, Nunez-Alvarez C, et al. Release of neutrophil extracellular traps by neutrophils stimulated with antiphospholipid antibodies: a newly identified mechanism of thrombosis in the antiphospholipid syndrome. Arthritis Rheumatol. 2015;67:2990-3003.

35. Zuo Y, Yalavarthi S, Gockman K, Madison JA, Gudjonsson JE, Kahlenberg JM, et al. Anti-Neutrophil Extracellular Trap Antibodies and Impaired Neutrophil Extracellular Trap Degradation in Antiphospholipid Syndrome. Arthritis \& Rheumatology. 2020;72:2130-5.

36. Wolach O, Sellar RS, Martinod K, Cherpokova D, McConkey M, Chappell RJ, et al. Increased neutrophil extracellular trap formation promotes thrombosis in myeloproliferative neoplasms. Sci Transl Med. 2018;11:10.

37. Pengo V. Antiphospholipid syndrome: interpretation of laboratory data. Journal of Thrombosis and Haemostasis. 2011;9:402-3.

38. Pengo V, Ruffatti A, Legnani C, Testa S, Fierro T, Marongiu F, et al. Incidence of a first thromboembolic event in asymptomatic carriers of high-risk antiphospholipid antibody profile: a multicenter prospective study. Blood. 2011;118:4714-8.

39. Rosove MH, Brewer PM. Antiphospholipid thrombosis: clinical course after the first thrombotic event in 70 patients. Ann Intern Med. 1992;117:303-8. 
40. Khamashta MA, Cuadrado MJ, Mujic F, Taub NA, Hunt BJ, Hughes GR. The management of thrombosis in the antiphospholipid-antibody syndrome. $\mathrm{N}$ Engl $\mathrm{J}$ Med. $1995 ; 332: 993-7$.

41. De Stefano V, Carobbio A, Di Lazzaro V, Guglielmelli P, lurlo A, Finazzi MC, et al. Benefit-risk profile of cytoreductive drugs along with antiplatelet and antithrombotic therapy after transient ischemic attack or ischemic stroke in myeloproliferative neoplasms. Blood cancer journal. 2018;8:1-12.

42. Sanchez-Redondo J, Espinosa G, Delgado DV, Cervera R. Recurrent Thrombosis With Direct Oral Anticoagulants in Antiphospholipid Syndrome: A Systematic Literature Review and Meta-analysis. Clin Ther. 2019;41:1839-62.

43. Dufrost V, Risse J, Zuily S, Wahl D. Direct oral anticoagulants use in antiphospholipid syndrome: are these drugs an effective and safe alternative to warfarin? A systematic review of the literature. Curr Rheumatol Rep. 2016;18:74. 